\title{
Procesos de patrimonialización en las exhibiciones antropológicas/ arqueológicas del Museo del Fin del Mundo (Tierra del Fuego, Argentina)
}

\section{Ana Butto y Danae Fiore $^{2}$}

\author{
${ }_{1}$ Consejo Nacional de Investigaciones Científicas y Técnicas, Centro Austral de Investigaciones Científicas. \\ Ushuaia, Argentina. \\ (iD) https:/orcid.org/oooo-0001-7455-909 \\ Correo electrónico: anabutto@gmail.com. \\ 2 Consejo Nacional de Investigaciones Científicas y Técnicas, Asociación de Investigaciones Antropológi- \\ cas, Universidad de Buenos Aires. Buenos Aires, Argentina. \\ (iD) https://orcid.org/0000-0003-1672-3070 \\ Correo electrónico: danae_fiore @yahoo.es
}

Recibido:

21 de febrero de 2020

Aceptado:

3 de agosto de 2020

doi: 10.34096/runa.v42i2.7605

\section{Resumen}

En este trabajo se analizan los artefactos producidos por poblaciones indígenas fueguinas expuestos en la exhibición antropológica/arqueológica del Museo del Fin del Mundo, ubicado en la ciudad de Ushuaia (Tierra del Fuego, Argentina), a fin de indagar en su proceso de patrimonialización como objetos museográficos. Para ello, se describe analíticamente dicha exhibición y se analizan: (a) los artefactos expuestos -arqueológicos, etnográficos y contemporáneos- y (b) la información escrita y visual asociada a dichos artefactos. De esta manera, se propone una aproximación a parte de los procesos de formación de la colección expuesta, centrándonos en discutir el proceso de selección y patrimonialización de estos objetos museográficos. Así, se indagan y discuten los contenidos, discursos e imaginarios que transmite el museo acerca del patrimonio cultural de los pueblos originarios fueguinos.

\section{Patrimonialization processes in the anthropological/archaeo- logical exhibitions at Museo del Fin del Mundo (Tierra del Fuego, Argentina)}

\begin{abstract}
In this paper we analyze the artifacts produced by the Indigenous peoples and displayed in the anthropological/archaeological exhibition of the Museo del Fin del Mundo, located in the city of Ushuaia (Tierra del Fuego, Argentina), in order to study their heritage process as museum objects. To this end, the anthropological and archaeological exhibits of the museum are presented and
\end{abstract}

Palabras clave

Museo; Patrimonio; Artefactos; Pueblos originarios; Tierra del Fuego

\section{Key words}

Museum; Heritage; Artifacts; Indigenous peoples; Tierra del Fuego 
analyzed systematically, including: a) the exhibited artifacts (archeological, ethnographic and contemporary) and b) the written and visual information associated with these artifacts. We thus address part of the formation processes of the exhibited collections, focusing the discussion on the object-selection choices and on their transformation into heritage and museum items. Thus, the contents, discourse and imaginary matters transmitted by the museum about the cultural heritage of the native Fuegian peoples are investigated and discussed.

\section{Processos de patrimonialização nas exposições antropoló- gicas/arqueológicas do Museo del Fin del Mundo (Terra do Fogo, Argentina)}

Palavras-chave

Museu; Patrimônio; Artefatos; Povos indígenas; Terra do Fogo

\section{Resumo}

Este trabalho analisa os artefatos produzidos por populações indígenas de Terra do Fogo expostas na exibição antropológica/arqueológica do Museo del Fin del Mundo, localizado na cidade de Ushuaia (Terra do Fogo, Argentina), a fim de investigar seu processo de patrimonialização como objetos de museu. Para esse fim, descreveremos as exposições antropológicas e arqueológicas do museu e analisaremos: a) os artefatos exibidos -arqueológicos, etnográficos e contemporâneos- e b) as informações escritas e visuais associadas a esses artefatos. Dessa forma, propõe-se uma abordagem de parte dos processos de formação da coleção exposta, com foco na discussão do processo de seleção e patrimonialização desses objetos museológicos. Assim, investigaremos e discutiremos os conteúdos, discursos e imaginários que o museu transmite sobre o patrimônio cultural dos povos indigenas da Terra do Fogo.

\section{Introducción: de artefactos, museos y patrimonio}

En este trabajo nos proponemos analizar la cultura material indígena -arqueológica, etnográfica y contemporánea- expuesta en las exhibiciones antropológicas y arqueológicas del Museo del Fin del Mundo (MFM), ubicado en la ciudad de Ushuaia (Tierra del Fuego, Argentina), con el propósito de indagar en el proceso de formación de la colección museológica expuesta y discutir las formas de selección y patrimonialización de esos objetos.

Entendemos que los museos son "instituciones sin fines de lucro al servicio de la sociedad y de su desarrollo, abiertas al público, que adquieren, conservan, investigan, comunican y exponen el patrimonio material e inmaterial de la humanidad y su medio ambiente con fines de educación, estudio y recreo" (Consejo Internacional de Museos, 2007:3). Ese patrimonio lo constituyen elementos y manifestaciones tangibles o intangibles heredadas del pasado que el museo identifica como reflejo y expresión de valores, creencias, conocimientos y tradiciones (Prats, 2004) propios -en el caso de las exhibiciones nacionales- y ajenos o exóticos -en el caso de las exhibiciones antropológicas y/o arqueológicas- (Quijada, 2012). Estos objetos, considerados como dignos de conservación, son un vehículo importante para la memoria y la transmisión 
de experiencias y conocimientos entre las generaciones (Endere, 2009; Reca, 2016), además de constituirse en vehículos de construcción y legitimación de discursos con funciones ideológicas (Bourdieu, 2010). De esta manera, toda exhibición museística supone decisiones que enfatizan algunos objetos y minimizan otros, aplican marcos teóricos y establecen estrategias interpretativas (Crespo y Tozzini, 2014). Los museos entonces generalmente escenifican una práctica histórica hegemónica que ignora, desconoce o niega otras formaciones históricas (Gnecco, 2001). En las Américas, la negación de estas otras memorias e historias responde a la inextricable relación entre los museos y los proyectos de construcción nacional, ya que los museos, como tecnologías de representación (Macdonal, 2006), son proactivos en la producción y reproducción de mitologías nacionales (Shelton, 2006) que colaboran en la creación de rituales de ciudadanía (Crespo y Tozzini, 2014).

Parte del patrimonio expuesto en exhibiciones antropológicas y arqueológicas está constituido por la cultura material de distintas sociedades e incluyen artefactos, es decir, objetos transportables producidos y/o formatizados por el trabajo humano en distintos momentos de sus historias, que se convirtieron en una dimensión integral de su cultura (Renfrew y Bahn, 1998; Tilley, 2006). En el caso de la cultura material de los pueblos originarios de territorios latinoamericanos, podemos distinguir tres categorías de artefactos, asociados con los momentos en los que han sido producidos y con las formas en que fueron obtenidos y registrados: (1) artefactos arqueológicos, vinculados al período precontacto occidental -también denominado precolombino o prehistórico- así como al período de contacto con sociedades occidentales -también llamado histórico- y que han sido rescatados mediante recolecciones de superficie o excavaciones arqueológicas; (2) artefactos etnográficos, vinculados a momentos de contacto con sociedades occidentales, y que han sido recolectados mediante compra-venta, trueque o robo para formar parte de diversas colecciones; y (3) artefactos contemporáneos, vinculados a momentos actuales o contemporáneos a la formación de la exhibición museográfica y que generalmente han sido obtenidos mediante compra o donación de artesanos, artistas, etc. (KirschenblattGimblett, 1998; Fiore y Butto, 2019). Ahora bien, para que un artefacto de cultura material -arqueológico, etnográfico o contemporáneo- sea considerado como objeto patrimonial e incluido en una colección museográfica, deben tener lugar ciertas decisiones y prácticas que pueden denominarse "procesos de formación de las colecciones museográficas" (Fiore y Butto, 2019). Esos procesos de formación incluyen: (1) selección de los objetos para su ingreso al museo (por adquisición, donación, robo, legado o préstamo); (2) ingreso de los objetos al museo; (3) registro e inventario; (4) salvaguarda y depósito; (5) conservación y puesta en valor; (6) selección para exhibición (permanente o temporaria) o para depósito; (7) salida/pérdida de objetos (intencional por donaciones o préstamos, no intencional por robo o eventos catastróficos, etc.); y (8) estudio de los objetos con fines científicos, escolares, identitarios, etc. Como resultado de la trayectoria a lo largo de estas etapas detalladas sintéticamente, un artefacto es retirado de su contexto cotidiano, es decir, su contexto sistémico (Schiffer, 1972) y puesto en un ambiente especial y distintivo para ser estudiado y exhibido. Así, al ingresar al museo, estos objetos ya no se rigen por su valor de uso, o sea, su valor basado en las necesidades y significados en la relación económica de hombre y medio ambiente; sino por su valor de cambio simbólico, operativo en la "economía del signo" (Baudrillard, 1975). En este nuevo contexto, los objetos pasan a ser "commodities" a los que se les asignan nuevos valores: autenticidad, antigüedad, orden taxonómico, estética y significación cultural (Clifford, 1985). La selección de los objetos museográficos implica entonces diferenciar entre los objetos reconocidos como valiosos 
1. Retomaremos la denominación étnica seguida por el Museo del Fin del Mundo. Sin embargo, cabe aclarar que los descendientes de la sociedad fueguina conocida como "Yámana” en la bibliografía arqueológica, antropológica e histórica, han elegido el término Yagán-que también aparece en algunas fuentes histórico-etnográficas- para su autodenominación. Cabe también aclarar que el término Selk'nam, difundido por Gusinde (1982), puede también referirse como Shelk'nam. y merecedores de protección institucional para su salvaguarda y exhibición -por considerarlos un testimonio del pasado propio y/o de sociedades que la anteceden y se desean transmitir a futuras generaciones- $\mathrm{y}$ aquellos que no lo son (Endere, 2009; Crespo y Tozzini, 2014).

Entendemos entonces que la selección y protección del patrimonio implica no solo la manipulación física de los objetos, sino también la negociación de valores y jerarquías, ya que están implicados tanto el contexto sociopolítico, como los discursos académicos, las legislaciones y los usos del pasado, que siempre son múltiples (Prats, 2004). Así, la patrimonialización, que puede definirse como el proceso por el cual se selecciona, activa y valoriza el patrimonio (Prats, 2004), implica la construcción de significados a lo largo de todo el proceso de formación de las colecciones, mientras dicho patrimonio es identificado, definido, manejado, exhibido, visitado y discutido (Reca, 2016). Esos procesos de patrimonialización tienden a ser multivocales cuando convocan a diversos agentes sociales: agentes estatales, agencias multilaterales, cientistas sociales, comunidad local y comunidades indígenas (Boccara y Ayala Rocabado, 2011; Rivolta, Montenegro, Menezes Ferreira y Nastri 2014; Fiore y Butto, 2019); o pueden ser procesos univocales y unilaterales, cuando los agentes estatales y especialistas definen el patrimonio "oficial", sin consultar ni hacer partícipes a las comunidades locales (Alonso González, 2017). Dado el rol preponderante del patrimonio en la construcción del pasado y la generación de identidades (Smith, 2006), consideramos de suma importancia estudiar de manera sistemática las exhibiciones museográficas dedicadas al patrimonio indígena fueguino.

Así, el foco de este trabajo es el patrimonio cultural -arqueológico, etnográfico y contemporáneo- producido por indígenas fueguinos y exhibido en la exposición antropológica/arqueológica del Museo del Fin del Mundo, donde se representan contenidos sobre dos pueblos originarios fueguinos: los Selk' nam y los Yámana. ${ }^{1}$ A fin de responder preguntas acerca de la patrimonialización de esos artefactos, centraremos el análisis en: (a) los objetos expuestos -arqueológicos, etnográficos y contemporáneos- y (b) los usos de la información escrita y visual asociada a esos objetos. Indagaremos en los procesos de formación de la colección museográfica expuesta y discutiremos su selección y patrimonialización. De esta manera, analizaremos los contenidos, discursos e imaginarios que presenta y transmite el Museo del Fin del Mundo sobre el patrimonio de los pueblos originarios fueguinos.

\section{Ushuaia y el Museo del Fin del Mundo}

El Museo del Fin del Mundo se encuentra en la ciudad de Ushuaia (Tierra del Fuego, Argentina), que se ubica en una región habitada tradicionalmente por el pueblo Yámana, que habitó y habita la porción meridional y oriental del archipiélago fueguino, desde la región del canal Beagle hasta el Cabo de Hornos (territorio actualmente dividido entre Argentina y Chile). En regiones vecinas habitaron y habitan otros pueblos originarios: los Selk'nam en el norte de la Isla Grande de Tierra del Fuego, los Haush en el sector suroriental de dicha isla y los Kawésqar en la parte occidental del archipiélago fueguino (Lothrop, 1928; Gusinde, 1982, 1986; Borrero, 1991; Orquera y Piana, 2015; Santiago y Salemme, 2016) (ver Figura 1).

La ciudad de Ushuaia se ubica en el extremo sur de la Isla Grande de Tierra del Fuego, a orillas del canal Beagle, y fue fundada en 1884, cuando el comandante argentino Augusto Laserre instaló la Subprefectura de Tierra del Fuego 


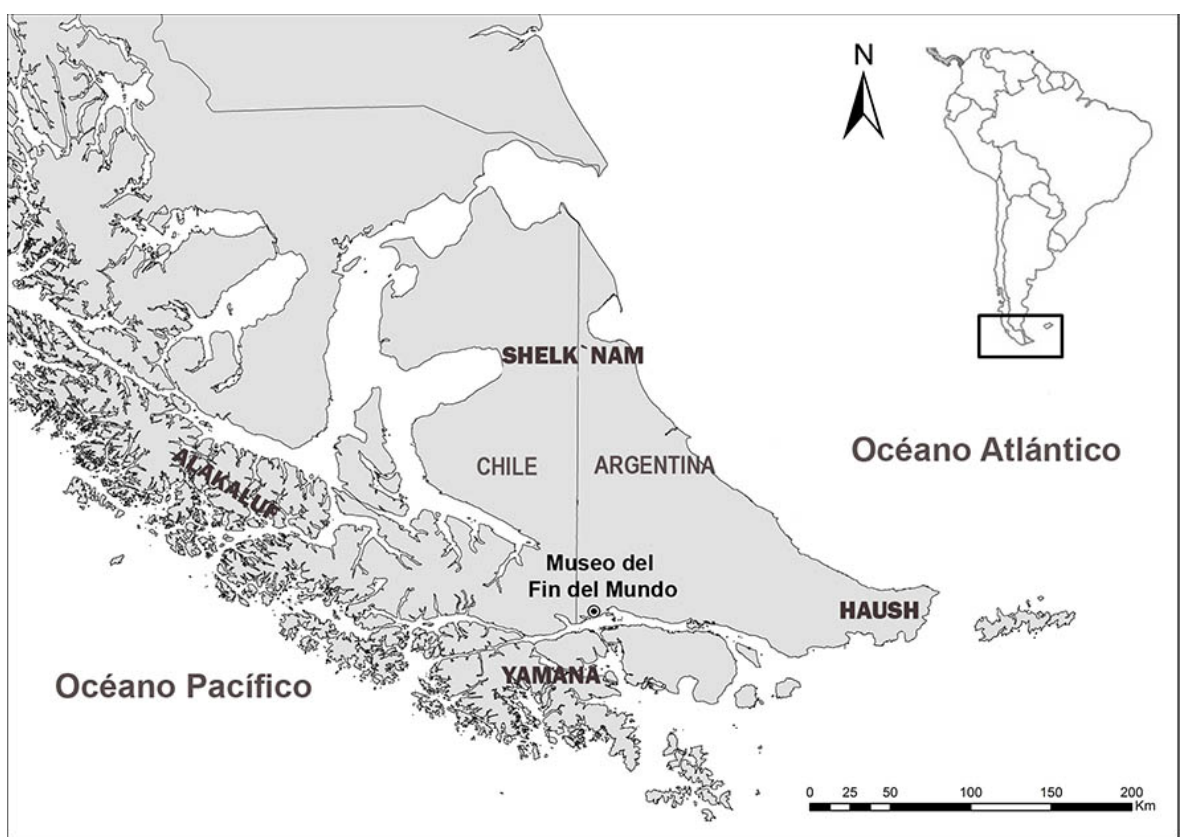

(Belza, 1974). Laserre formaba parte de la División Expedicionaria del Atlántico Sud de la Marina Argentina, enviada por el presidente Julio Roca con el objetivo de reconocer el territorio fueguino y fundar ciudades que sirvieran como reclamo soberano de aquel territorio. Se instalaron entonces una subprefectura y un faro en la Isla de los Estados y una subprefectura en la bahía de Ushuaia, que permitiera la presencia permanente del Gobierno argentino (Belza, 1974). La elección de esta bahía para fundar la subprefectura tuvo como antecedente la instalación previa (en 1869) de una misión anglicana (Bridges, 2005), ${ }^{2}$ a la cual el Gobierno argentino ofreció las garantías necesarias para continuar ejerciendo su labor (Belza, 1974).

Junto con la fundación de Ushuaia se creó la Gobernación de Tierra del Fuego, que en 1957 se convertiría en el Territorio Nacional de Tierra del Fuego, Antártida e Islas del Atlántico Sur y recién en 1990 pasaría a ser la Provincia de Tierra del Fuego, Antártida e Islas del Atlántico Sur. Se desconoce la población inicial de Ushuaia, pero el segundo Censo Nacional de 1895 indicó un total de 447 habitantes occidentales en toda la isla de Tierra del Fuego. En ese censo no se contabilizaron los habitantes indígenas, pero el misionero anglicano Thomas Bridges había registrado en 1884 poco más de mil habitantes yámanas en territorio tanto argentino como chileno, y subrayó que veinte años antes habrían sido alrededor de tres mil (Bridges, 2005). Desde aquellos primeros momentos, Ushuaia continuó su crecimiento y el Censo Nacional de 2010 relevó un total de 127.205 habitantes para toda la provincia de Tierra del Fuego, de los cuales 56.956 habitaban en Ushuaia, actual capital de la provincia. En ese censo, un total de 1124 personas se autorreconocieron como descendientes de pueblos originarios en la Provincia de Tierra del Fuego.

El Museo del Fin del Mundo fue creado en 1979, aunque la intención de su creación data de 1906, cuando se conformó la primera comisión Pro-Museo de Ciencias Naturales y Biblioteca Pública de Ushuaia, con el objetivo de encontrar un espacio para las incipientes colecciones de materiales naturales y culturales. Las distintas peticiones fueron negadas desde el Gobierno nacional, hasta que en 1979 se fundó el Museo Territorial, luego devenido en Museo del Fin del Mundo. Al momento de su fundación el museo dependía del Gobierno del
Figura 1: Mapa de Tierra del Fuego y ubicación del museo

2. La elección de la bahía de Ushuaia para la instalación de la misión anglicana también estuvo supeditada a una habitación previa del espacio, la de los Yámana, preexistentes en la región. 
3. Información consultada en la página oficial del museo: www. mfm.tierradelfuego.gov.ar.
Territorio Nacional de Tierra del Fuego, Antártida e Islas del Atlántico Sur (AIAS), y en la actualidad depende de la Secretaría de Cultura de la Provincia de Tierra del Fuego AIAS.

Desde su creación, se enfatizaron las ansias de los fueguinos por contar con un espacio donde se exhibieran los bienes patrimoniales de la región. ${ }^{3}$ El museo ocupa en la actualidad dos espacios: el antiguo edificio del Banco de la Nación Argentina, que fue cedido por el Gobierno del Territorio Nacional de Tierra del Fuego AIAS y es la sede original del museo desde 1979, y la antigua Casa de Gobierno, donde más tarde funcionó la Legislatura Territorial y Provincial, que fue cedida como anexo del museo en el año 2008. Así, ambas sedes catalizan la memoria asociada a sus antiguos dueños y a las vidas pasadas de esos espacios (Shelton, 2006), tan importantes para la historia fueguina. Las colecciones que resguarda el museo se organizaron sobre la base de donaciones de particulares y de colecciones generadas por investigadores del Consejo Nacional de Investigaciones Científicas y Técnicas (CONICET) y del Centro Austral de Investigaciones Científicas (CADIC). En la sede central Banco Nación se encuentra la exposición permanente, dos salas de muestras temporarias y un espacio audiovisual. La exposición principal incluye: fauna autóctona, objetos arqueológicos de los primeros pobladores de la región, objetos etnográficos de los Pueblos Originarios Fueguinos y otros pertenecientes a los primeros viajeros europeos que recorrieron la región. En la sede Antigua Casa de Gobierno se exhiben objetos asociados a la historia de la ciudad, como muebles, cuadros y el escritorio original del primer Gobernador.

Centraremos el análisis en la exhibición principal de la sede Banco Nación, que abarca desde el poblamiento de la región patagónico-fueguina en momentos prehistóricos hasta los primeros contactos entre los Pueblos Originarios Fueguinos y los exploradores occidentales. Nos interesa especialmente indagar en las secciones antropológicas/arqueológicas, en tanto consideramos que permiten una aproximación y discusión de las formas de exhibición, valoración y divulgación del patrimonio indígena fueguino.

\section{Método y visita al museo}

La recolección, registro, análisis y evaluación de los datos se realizaron siguiendo un lineamiento metodológico propio, a fin de responder las preguntas acerca del patrimonio indígena fueguino desde una perspectiva centrada en su materialidad (Endere, 2009).

La formación de esta muestra de datos implicó la visita personal al Museo del Fin del Mundo en febrero de 2013, octubre de 2015 y marzo de 2017, con el aval de sus directores en cada momento. Se visitó y registró la totalidad de la exposición permanente de la sede Casa Banco Nación enfatizando en las secciones antropológicas/arqueológicas.

El registro de los datos se realizó mediante las siguientes tareas: (a) el recorrido de las distintas secciones de la exhibición permanente del museo en el orden propuesto desde el guion museográfico, poniendo especial énfasis en las secciones antropológicas/arqueológicas dedicadas a los Pueblos Originarios Fueguinos; (b) la confección de un mapa de la exhibición, señalando la ubicación y relación entre las secciones; (c) el registro escrito y visual de los textos introductorios de las distintas secciones; (d) el registro escrito y visual de los artefactos expuestos y sus epígrafes; (e) el registro del tipo de artefactos 
expuestos -arqueológicos, etnográficos, contemporáneos-; (f) el registro escrito y visual de las imágenes -mapas, diagramas, dibujos, grabados y fotografías- y sus epígrafes y ( $\mathrm{g}$ ) el registro de las relaciones entre artefactos, textos e imágenes. Dado que la relación entre galerías, pasillos y vitrinas estructuran la circulación y secuencia de la visita (Shelton, 2006), todas las secciones de la exhibición fueron analizadas y registradas, a fin de obtener un panorama general de la exposición museográfica, aunque el análisis se centra en las secciones antropológicas/arqueológicas.

Así, el análisis de los datos registrados sobre las secciones dedicadas a los Pueblos Originarios se enfocó en las siguientes variables: (a) los artefactos expuestos -arqueológicos, etnográficos y contemporáneos-; y (b) los usos de la información escrita y visual asociada a esos artefactos. De esta manera, analizamos el tratamiento dado a los distintos tipos de artefactos expuestos y a la información escrita y visual que los acompaña, a fin de indagar en el proceso de formación de la colección museográfica (Fiore y Butto, 2019) expuesta y discutir su proceso de selección y patrimonialización.

\section{De artefactos fueguinos a objetos museográficos}

\section{La exhibición: un recorrido completo}

A fin de desarrollar el análisis del patrimonio indígena exhibido en el Museo del Fin del Mundo, describiremos la exposición permanente, para luego centrar el análisis en las secciones antropológicas/ arqueológicas a partir de las variables arriba mencionadas.

La exposición principal de la sede "Banco Nación" se compone de seis secciones, que abarcan: (1) la flora y fauna autóctona; (2) el primer poblamiento de la región patagónico-fueguina; (3) los Pueblos Originarios Fueguinos -Selk'nam y Yámana-; (4) los misioneros anglicanos y salesianos; (5) los exploradores marinos y terrestres; y (6) los naufragios (ver Figura 2). De éstas, las secciones $\# 2$ y \#3 son las secciones antropológicas/arqueológicas que analizaremos aquí.

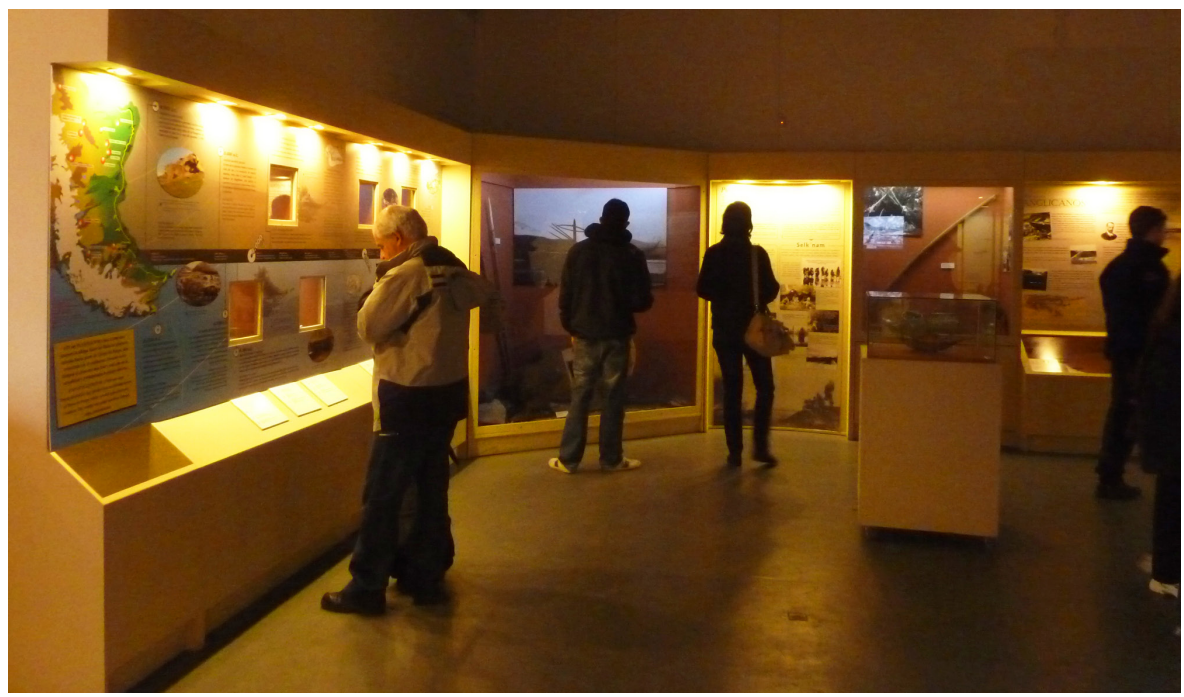

Figura 2: Fotografía general de la exhibición permanente del Museo del Fin del Mundo. 
4. Si bien la cronología de eventos prehistóricos suele medirse en años AP (antes del presente), en esta exhibición la cronología está organizada en antes y después de Cristo.

5. Esta reducción puede comprenderse a la luz del escaso conocimiento histórico-etnográfico que se tiene acerca de los Haush y al hecho de que la región habitada por los Kawésqar se sitúa actualmente en territorio chileno. En este último caso, esta exclusión refuerza la idea de que el museo prioriza la presentación de los Pueblos Originarios Fueguinos que constituyen actualmente parte del Estado nación argentino.
Al comienzo de la exposición principal se ubica un mapa de la región patagónico-fueguina que muestra los cambios climáticos de los últimos 12.000 años. La sección \#2 está dedicada al poblamiento inicial de la región y muestra una línea cronológica horizontal que comienza en el 8000 a. C. ${ }^{4}$ y conecta los procesos regionales fueguinos con algunos grandes eventos prehistóricos mundiales (e.g., la "revolución neolítica" y la escritura cuneiforme). Así, se vinculan episodios paleoclimáticos -como las modificaciones en el nivel del mar-con eventos biológicos -la extinción de la megafauna pleistocénica, por ejemplo-y con acontecimientos culturales locales -como los vestigios arqueológicos más antiguos de la presencia humana en Tierra del Fuego (registrados en 8500 a. C.)-. Esta línea de tiempo incluye un mapa de los sitios arqueológicos más tempranos de la región patagónico-fueguina y pequeñas vitrinas en las que se exponen artefactos arqueológicos excavados en sitios de Tierra del Fuego. En esta sección se incluyen distintos tipos de materiales: artefactos y restos de fauna arqueológicos, esquemas de enterratorios, fotografías de las excavaciones e ilustraciones del siglo XVII. La línea cronológica finaliza en dos fechas significativas: 1580, momento del encuentro de la expedición del explorador español Sarmiento de Gamboa con personas selk' nam en las costas del estrecho de Magallanes y 1624, fecha del encuentro de la expedición holandesa de L'Hermite con personas canoeras, que por su lugar de encuentro (la isla Hoste) podemos considerar yámanas. Ambos acontecimientos están ilustrados con grabados y dibujos de esa época, ubicados alrededor de un mapa de Tierra del Fuego que muestra la distribución etnográficamente conocida de los Pueblos Originarios Fueguinos: los Selk'nam u Onas en el centro de la Isla Grande de Tierra del Fuego, los Mannek'enk o Haush en la costa sudoriental, los Yámana o Yagán en la costa del canal Beagle y las islas de los canales fueguinos orientales y los Kawéskar o Alakaluf en las islas de los canales occidentales (los nombres y distribución de los pueblos están en la Figura 1).

La sección \#3 de la sala principal, que ocupa dos vitrinas, está dedicada a dos de los Pueblos Originarios Fueguinos señalados en la Figura 1: los Yámana y los Selk' nam. Así, la variabilidad de pueblos originarios presentada en el mapa etnográfico se reduce a solo dos pueblos en esta sección. ${ }^{5}$ Estas vitrinas exhiben objetos etnográficos y contemporáneos representativos de cada sociedad: artefactos asociados al modo de vida canoero -como arpones y cestas- en el caso yámana, y artefactos de caza y recolección terrestres -como arcos, flechas, bolsas de cuero y cestas- en el caso selk'nam. En el centro de ambas vitrinas hay un afiche que describe el modo de vida tradicional de estos dos pueblos originarios a través de textos y fotografías etnográficas.

La sección \#4, dedicada a los misioneros anglicanos y salesianos, consta de dos afiches que relatan algunos eventos relacionados con la labor misional en Tierra del Fuego: el desembarco del misionero anglicano Allen Gardiner en el Canal Beagle, la fundación de la misión anglicana de Ushuaia, el arribo de Thomas Bridges y el desarrollo de su diccionario yámana-inglés, el arribo del misionero salesiano José Fagnano y la fundación de las misiones salesianas de Isla Dawson y Río Grande. Se exponen además nueve fotografías de esas misiones y algunos objetos relacionados con el culto católico: una estatuilla de una virgen, una prensa de hostias y un diario con las crónicas salesianas.

La sección \#5, dedicada a los exploradores marinos y terrestres, consta de una línea cronológica que comienza en 1520 con la primera exploración europea de Tierra del Fuego por Hernando de Magallanes y culmina en 1884 con la exploración de la División Expedicionaria del Atlántico Sud de la Marina Argentina. Junto al afiche hay un mapa con la ubicación de los primeros encuentros entre 
indígenas fueguinos y exploradores europeos, en el que se señala el lugar, la fecha y el explorador protagonista del encuentro. La vitrina dedicada a los exploradores terrestres refiere al italiano Giácomo Bove, quien encabezó la Expedición Austral Argentina en 1881-1882 que recorrió Tierra del Fuego con fines científicos y exploratorios; al militar argentino Ramón Lista, quien recorrió el territorio fueguino en 1886 con fines exploratorios; y al ingeniero rumano Julius Popper, que a partir de 1886 realizó explotaciones auríferas, organizó su propia fuerza armada y emitió sus propias monedas y estampillas. En el piso de la vitrina se exhibe un laboratorio médico de campaña, una carabina utilizada en la expedición de Lista y cuños y monedas impresas por Popper. Resulta llamativa la ausencia de referencias a los encuentros violentos y matanzas de indígenas fueguinos que protagonizaron estos exploradores (Belza, 1974). Como discutiremos más adelante, la omisión de los ataques violentos a manos de agentes occidentales (europeos y criollos) de la que fueron objeto las comunidades indígenas funciona como un silenciamiento de los procesos conflictivos que conformaron la historia fueguina, pero que no son visibilizados en los dispositivos de la exhibición (Crespo y Tozzini, 2014). La sección \#6 está dedicada a los restos de naufragios, donde se exhibe la proa del Duchess of Albany, un buque inglés que naufragó en 1893 en las costas de la península Mitre, además de un ladrillo, una botella de vidrio, botones, sellos en textiles, pipas de cerámica y fragmentos de botellas de vidrio.

\section{Las secciones antropológicas/arqueológicas: un análisis con- textual de su materialidad}

Del total del guion del Museo del Fin del Mundo, las secciones \#2 y \#3 exponen temáticas antropológicas/arqueológicas centradas en los Pueblos Originarios Fueguinos, que analizaremos siguiendo las variables expuestas en el acápite metodológico.

Los artefactos arqueológicos son exhibidos solo en la sección \#2, dedicada al poblamiento de la región fueguina, y no se repiten en otras secciones, con lo cual entonces solo quedan asociados al pasado remoto y prehistórico. La sección, que está organizada a partir de una línea de tiempo horizontal, se divide en dos subsecciones ordenadas verticalmente: la subsección superior está dedicada a las "Ocupaciones antiguas en la estepa", es decir, las ocupaciones del norte de la isla, donde en tiempos históricos habitaron los Selk'nam; y la subsección inferior está dedicada a los "Nómades del mar: los canoeros", es decir, las ocupaciones del canal Beagle y alrededores, donde en tiempos históricos habitaron los Yámana.

Los objetos arqueológicos exhibidos en la subsección superior, dedicada a los cazadores de la estepa, son (de acuerdo con las descripciones de los epígrafes): una bola arrojadiza con surco, una raedera, un mortero, un machacador de hueso de guanaco, una punta lítica de obsidiana verde, un alisador de astiles de hueso, seis puntas líticas, una punta vítrea y dos cuentas de collar de hueso de ave con decoración (ver Figura 3). Estos artefactos fueron hallados en cuatro sitios arqueológicos: La Arcillosa, Las Vueltas, Amalia y Cabeza de León, que abarcan desde los 3600 hasta los 900 años AP (antes del presente).

Por otro lado, los objetos arqueológicos de la subsección inferior dedicada a los canoeros incluyen (de acuerdo con los epígrafes): un trinchete, cuatro puntas óseas de arpón (dos de base cruciforme, una multidentada y una de espaldón simple), un punzón confeccionado sobre hueso de ave, cuatro puntas líticas, 
Figura 3: Fotografía de la vitrina arqueológica dedicada al poblamiento inicial de la región fueguina. una raedera y un conjunto de puntas líticas parte de un ajuar funerario (ver Figura 3). Estos artefactos fueron hallados en tres sitios arqueológicos excavados en la región del canal Beagle: Mischiúen I, Shamakush VIII y Shamakush Enterratorio, que abarcan desde los 4900 hasta los 800 años AP.

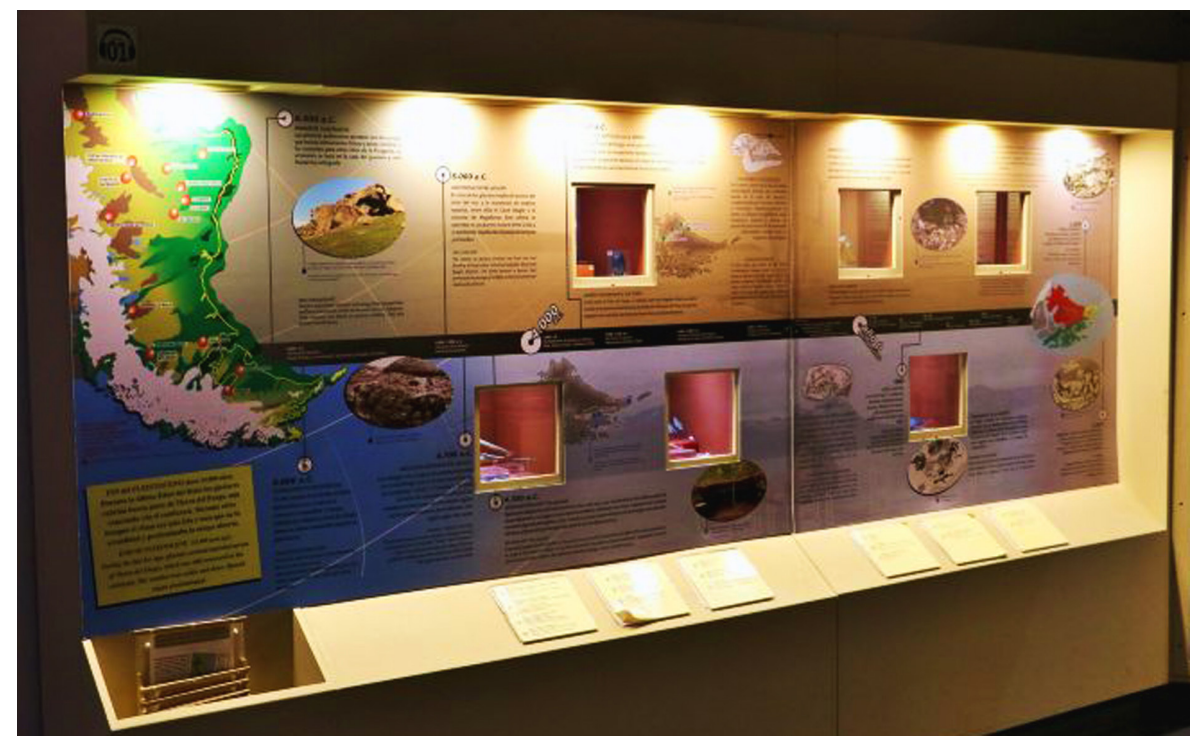

Al analizar esta colección arqueológica encontramos que se incluyen artefactos especialmente referidos a la subsistencia cazadora: los vinculados a los cazadores del norte de la isla están dedicados a la subsistencia cazadora terrestre, en tanto los procedentes de la región del canal Beagle denotan una subsistencia más centrada en los recursos marinos (relacionados con el uso de arpones) pero también terrestres (relacionados con el uso de puntas líticas). Sin embargo, la colección canoera también muestra un punzón en hueso de ave, artefacto ubicuo en los sitios del canal Beagle (Orquera y Piana, 2015), utilizado presumiblemente para la confección de cestas de junco. Este objeto referencia así la recolección de vegetales y/o moluscos que se efectuaba con cestas.

La información escrita y visual que acompaña la exhibición de estos artefactos es numerosa e importante, ya que el soporte es una línea de tiempo sobre la cual se ordenan y describen los eventos culturales de forma escrita. Los epígrafes describen a las primeras poblaciones que habitaron la estepa del norte de la isla y el litoral marítimo, refieren a sus vestigios más antiguos y enfatizan que se trató de campamentos efímeros de poblaciones con tecnología de instrumentos líticos y óseos. Se presenta posteriormente la conformación de dos modos de vida adaptados a sus respectivos medioambientes alrededor del 4000 a. C. -uno cazador de guanacos y otro canoero- y se refiere al incremento poblacional ocurrido alrededor del 2500 a. C., explicando que se dio la ocupación total y efectiva de la isla. El uso del arco y flecha es señalado como un evento importante alrededor del 600 d. C., con las primeras evidencias en el sitio Alej I, pero no se mencionan los avances que implica esta tecnología para la caza. La serie de datos escritos culmina con las primeras fechas de contacto de estas dos poblaciones con exploradores europeos.

Todos estos desarrollos culturales se conectan con los objetos arqueológicos ubicados en las vitrinas y con elementos visuales como mapas, dibujos, grabados y fotos. Así, la palabra escrita y las fechas de la línea de tiempo aportan el orden cronológico que da contexto a los artefactos exhibidos. Los epígrafes 
que acompañan la exhibición de estos artefactos son los más descriptivos e informativos de todas las secciones: indican el tipo de objeto, función, materia prima, sitio arqueológico donde fue hallado y antigüedad. En tal sentido, esta forma de exhibición reproduce una lógica netamente arqueológica, en la cual la clasificación de materiales se organiza por ejes témporo-espaciales, materias primas, morfología y función.

La información visual es muy importante también y la hay de diferentes tipos. El primero de ellos está conformado por los mapas: uno de Patagonia y Tierra del Fuego, con la localización de 16 sitios arqueológicos tempranos y dos mapas de Tierra de Fuego, con la localización de cinco sitios de cazadores pedestres del norte de la isla y de cuatro sitios de canoeros de la región del canal Beagle. Hacia el final de la línea de tiempo se ubica un último mapa de la región fueguina, con la localización de los territorios etnográficamente conocidos de los cuatro Pueblos Originarios Fueguinos en tiempos históricos (post siglo XVI).

En cuanto a los materiales gráficos, se incluye el dibujo del sitio Shamakush Enterratorio, en el que un cuerpo enterrado yace al lado de muchas puntas líticas. Estas puntas se encuentran en la vitrina de vidrio inmediatamente contigua e interrelacionan de manera complementaria los artefactos exhibidos con la información visual, lo que le brinda al visitante una imagen más completa de la significación cultural de los hallazgos. Además, se incluyen dos dibujos de anatomía zoológica: un cráneo de guanaco en la parte dedicada a los cazadores-recolectores pedestres y un cráneo de lobo marino en la parte dedicada a los cazadores-recolectores canoeros. La sección incluye una fotografía del sitio arqueológico Tres Arroyos y una reconstrucción gráfica de la apariencia de la megafauna que habitaba el norte de la isla, ubicadas próximas a las vitrinas con objetos encontrados en los sitios del norte de la Isla Grande en asociación con restos de megafauna, es decir, de mayor antigüedad que los restantes artefactos allí exhibidos. Otras dos fotografías son las del perfil de excavación ${ }^{6}$ del sitio Bahía Valentín Sitio 11 y la de la planta del sitio ${ }^{7}$ Las Vueltas I, donde se observan los restos de una cacería masiva de guanacos. Así, los materiales de las vitrinas se conectan con las imágenes de los sitios excavados, lo cual permite una aproximación al contexto y método arqueológico con que fueron recuperados esos artefactos devenidos en objetos patrimoniales.

Los últimos elementos visuales son, como dicen los epígrafes, reproducciones de grabados e ilustraciones del siglo XVII, que representan, en uno de los casos, un paisaje del Estrecho de Magallanes, y en el otro, a grupos canoeros del extremo sur. Resulta llamativo que en ninguno de los dos casos aparezcan mencionados los autores de los grabados ni tampoco su procedencia, ${ }^{8}$ dejando estas imágenes exclusivamente como ilustraciones de lo que el público ya conoce a través de la palabra escrita o de los objetos arqueológicos exhibidos.

Los objetos etnográficos expuestos ocupan la mayor parte de la sección \#3, dedicada a los Pueblos Originarios que habitaron Tierra del Fuego entre los siglos XVI y XX. En esta sección se invierte el orden y, siguiendo el recorrido diseñado, la vitrina dedicada a los Yámana está antes que la vitrina de los Selk'nam. Como ya dijimos, en el medio de ambas se ubica un afiche que describe el modo de vida tradicional de estas sociedades. La vitrina dedicada a los Yámana exhibe objetos relacionados con el modo de vida cazador-recolector canoero: lobos marinos, arpones y cestas (ver Figura 4). La exposición central incluye una
6. El perfil estratigráfico de la excavación de un sitio arqueológico muestra en un corte vertical las capas de sedimento acumuladas a lo largo del tiempo, mostrando la sucesión temporal de los contextos arqueológicos (Harris, 1991).

7. La planta de un sitio es la vista de los niveles horizontales de una excavación, donde se puede ver la ubicación exacta de los artefactos y restos excavados (Renfrew y Bahn, 1998).

8. El grabado del sur de Tierra del Fuego se titula "Hombres de Tierra del Fuego" y fue realizado en 1599 por un autor desconocido de origen holandés, pero la ilustración del Estrecho de Magallanes es de autor y fecha desconocida. 
puesta en escena de dos lobos marinos (Otaria flavescens) embalsamados -un adulto y una cría-, en un espacio de rocas que simula la costa del canal Beagle. En la pared de la derecha de la vitrina se exhibe una fotografía etnográfica que muestra una gran canoa yámana en una playa de guijarros con varios arpones y remos entrelazados. Sobre la pared izquierda se exhiben dos arpones: uno con punta ósea monodentada y otro con punta ósea multidentada; según información provista en los epígrafes, se trata de réplicas contemporáneas. Al lado de los arpones, sobre dos pequeñas repisas de acrílico, se exhiben dos cestas de diferentes tamaños, cuyos epígrafes informan que están confeccionadas con junco mediante técnica de espiral, pero no mencionan su autoría, por lo que su carácter etnográfico es inferible a partir de que no se trataría de artefactos arqueológicos (debido a que su materia prima impediría su preservación) y tampoco son señalados como réplicas, como sí lo son los arpones.

Figura 4: Fotografía de las vitrinas yámana y selk'nam.

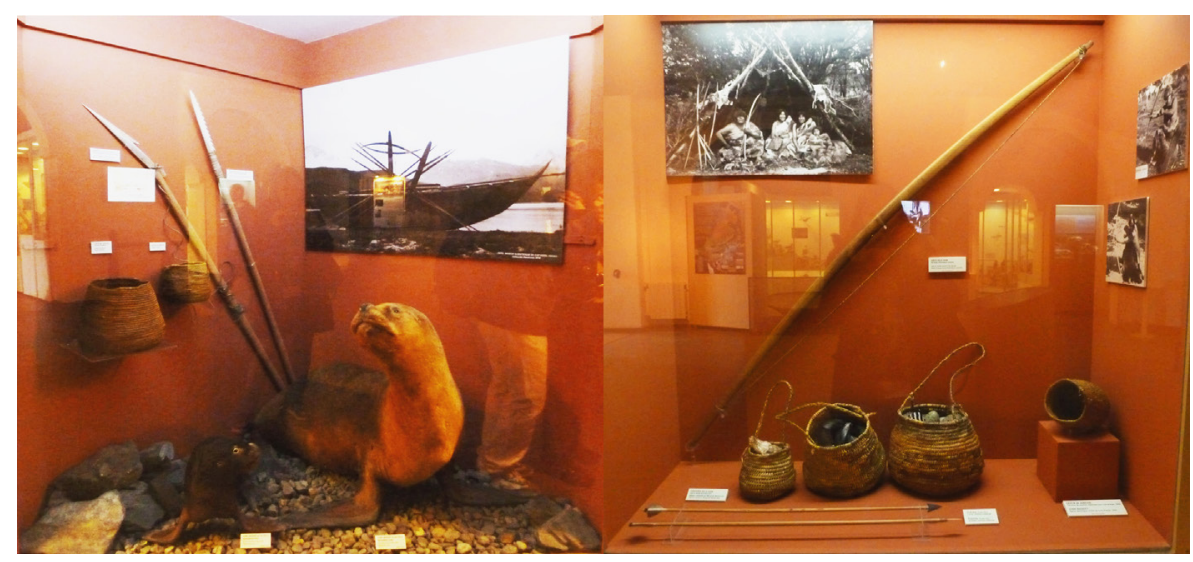

Por otro lado, la vitrina dedicada al pueblo Selk'nam exhibe objetos e imágenes característicos del modo de vida cazador-recolector pedestre, aunque con una puesta en escena menor (ver Figura 4). En la pared de la vitrina se exhibe una fotografía de una familia selk'nam sentada dentro de una choza, vestidos a la usanza tradicional, con mantos de guanaco, y manipulando arcos y flechas, bolsas de cuero y cestas. Estos mismos tipos de artefactos aparecen expuestos: un arco de madera de lenga con su tensa cuerda anudada a los extremos ocupa todo el fondo de la vitrina, lo cual subraya su gran tamaño; en el piso se exhiben dos flechas con punta de tipo triangular (una lítica y otra ósea) enmangadas en astiles de madera. Los epígrafes solo mencionan el tipo de artefacto y la materia prima, sin aportar datos sobre su antigüedad ni del artesano/a que los confeccionó. Detrás de las flechas se exhibe una cesta vacía, cuyo epígrafe informa que fue confeccionada en 1960 por Lola Kiepja, respecto de quien no se aporta información: se trata de una mujer selk'nam que fue una informante clave de la antropóloga franco-estadounidense Anne Chapman durante sus trabajos de campo en Tierra del Fuego, desarrollados en las décadas de 1960-1970. Así, los epígrafes de ambas vitrinas incluyen la misma clase de información: tipo de objeto, materia prima, técnica de confección y (a veces) fecha, además de aclarar si se trata de réplicas. Pero también, en el caso de la cesta arriba mencionada, se aportan datos sobre su productora, aunque sin otorgar mayor contexto, y se proporciona información parcial sobre el origen etnográfico del objeto.

La información escrita y visual que acompaña estos objetos etnográficos de la sección \#3 presenta un tratamiento muy distinto a la de la sección \#2. En el afiche ubicado en medio de las vitrinas dedicadas a los Yámana y Selk'nam 
se describe a esas sociedades como se las conoció hacia fines del siglo XIX y comienzos del XX. El texto comienza con una referencia poética a estos pueblos como "herederos de tradiciones arraigadas en la profundidad del tiempo" y enfatiza en la diversidad de sus culturas. Luego de esta introducción conjunta, el afiche se divide en dos: una sección dedicada a los Yámana y otra a los Selk'nam. El texto destinado a los Yámana subraya el modo de vida nómade canoero, la subsistencia basada en la captura de lobos marinos y la organización social basada en la familia, e incluye referencias a las ceremonias de iniciación (el chiéjaus y el kina) y la pintura corporal usada en esas ceremonias. Por otro lado, el texto dedicado a los Selk' nam se centra en la subsistencia basada en la caza de guanacos, en la organización social, la territorialidad, y enfatiza la vida ceremonial, tanto respecto del poder de los shamanes como de la ceremonia de iniciación masculina (el hain) y los espíritus que se personificaban en ella.

La información visual incluida se restringe a un único tipo: las fotografías etnográficas, presentes tanto en las vitrinas como en el afiche. En este último se incluyen seis fotografías etnográficas en la sección yámana y seis en la selk'nam: en ambos casos, tres fotografías representan escenas de la vida cotidiana, y tres, de la vida ceremonial. En el caso de los Yámana, las tres imágenes que representan la vida cotidiana muestran canoas y la única fotografía de la vitrina -que, como señala su epígrafe, fue obtenida por la Misión Científica Francesa en 1882/3- muestra también una canoa con remos y arpones, para referir al modo de vida canoero. En el afiche, una de las imágenes muestra a un varón yámana manipulando un arpón, lo que ayuda a referenciar los arpones exhibidos en la vitrina contigua. Las otras tres imágenes muestran escenas del chiejaus y el kina, dos ceremonias de iniciación fotografiadas por el etnógrafo alemán Martin Gusinde en 1921-1922. Estas imágenes no encuentran referencia en ninguno de los objetos etnográficos exhibidos, ya que la vitrina no muestra artefactos ceremoniales. Esta ausencia se conecta con el hecho de que muy pocos exploradores tuvieron acceso a las ceremonias yaganes $\mathrm{y}$, por lo tanto, muy pocos recolectaron y coleccionaron artefactos relacionados con ellas. El resto de las fotografías no tienen epígrafe, lo que enfatiza su uso como ilustración y no como fuente de información (Burke, 2005; Fiore y Varela, 2009; Butto, 2019).

En el caso de los Selk'nam, tres de las fotografías etnográficas incluidas en el afiche muestran grupos de cazadores con capas de guanaco y arcos y flechas, para referir al modo de vida cazador. Las otras tres muestran escenas de la ceremonia de iniciación del hain, también retratada y registrada por el etnógrafo alemán Martin Gusinde en 1923. Las imágenes del hain tampoco pueden ser referenciadas a ningún objeto exhibido en la vitrina contigua, que no incluye artefactos ceremoniales. La observación de esta ceremonia por occidentales fue aún menor que en el caso yámana, lo cual reduce significativamente la posibilidad de coleccionar objetos ceremoniales. La vitrina en la que se exponen los objetos etnográficos selk'nam también incluye tres fotografías: la imagen más grande en el fondo de la vitrina fue tomada por Alberto De Agostini entre 1910 y 1920 (autoría y fecha que no aparecen en la vitrina, ya que no tiene epígrafe). Ésta retrata una familia selk' nam dentro de una choza, vestidos con tradicionales mantos de guanaco y manipulando arcos y flechas, bolsas de cuero y cestas, lo cual permite referenciar los artefactos exhibidos en la vitrina a esos documentados en las imágenes. Las dos fotografías ${ }^{9}$ ubicadas en la pared lateral muestran cazadores selk'nam empuñando arcos y flechas posando como cazadores: en una de las imágenes sostienen sus carcajes (estuches portaflechas) con la boca, mientras que en la otra lo tienen apoyado en la pierna
9. La autoría de las imágenes no aparece en las vitrinas, ya que ninguna de ellas cuenta con epígrafe. Una de esas fotografías pertenece al misionero salesiano Alberto De Agostini (tomada entre 1910 y 1918) y otra al etnógrafo alemán Martin Gusinde (tomada entre 1918 y 1924) (datos del archivo ARC-FOT-AIA). 
izquierda. De esta manera, el arco etnográfico expuesto puede referenciarse en los de las fotos, lo que permite al visitante imaginar el uso de esos objetos en la práctica. Llama la atención el énfasis puesto en las imágenes masculinas de caza, mientras la vitrina exhibe en realidad mayor cantidad de artefactos asociados a las tareas femeninas, como las cestas usadas en la recolección de moluscos y vegetales (Borrero, 1991; Butto, 2019). Así, ni en la vitrina ni en el afiche se incluyen imágenes que refieran a las tareas femeninas, aunque varios de los artefactos etnográficos exhibidos -como las cestas- sí estén asociados a esas tareas. De esta manera, se enfatiza la representación visual y material de la caza, actividad eminentemente masculina que vincula a los varones con las grandes presas, la habilidad tecnológica y la fortaleza corporal, a la vez que se invisibiliza el rol femenino en las tareas de recolección, al no aportar información sobre el género de quienes las realizaban (Butto, Saletta y Fiore, 2018).

Los objetos contemporáneos se encuentran en exhibición en la sección \#3 y son piezas vinculadas con los Yámana y los Selk'nam. En la vitrina dedicada a los Yámana se exhiben dos arpones: uno con punta ósea de base separable monodentada, ligada al mango de madera con una cuerda de tendón, y otro con punta ósea de base fija multidentada, atada al mango con una cuerda de tendón (Lothrop, 1928; Gusinde, 1986). El epígrafe informa que estos objetos fueron confeccionados por Kauel Moll Werken, pero no indica que se trata de un artesano mapuche residente en Ushuaia (M. Vázquez, comunicación personal, 2013). A su vez, el museo encargó la confección de arpones al artesano yagán Martín González Calderón, experto en la producción de este tipo de instrumental óseo e integrante de la Comunidad Yagán de Bahía Mejillones (Puerto Williams, Chile). Sin embargo, dichos artefactos no habían arribado en el año 2013, cuando realizamos el relevamiento (M. Vázquez, comunicación personal, 2013) ni en 2017, cuando volvimos a visitar el museo. Así, entendemos que la exhibición museográfica de este arpón -denominado "réplica" en los epígrafes de la exhibición- refiere a un proceso de patrimonialización especial, en el cual la similitud morfológica con los arpones tradicionales y la identidad indígena del artesano constituirían valores más importantes que la "autenticidad" de la pieza y que la identidad étnica específica de sus productores (es así como parece ser más relevante que el artesano sea indígena pero parece resultar indistinto si es Mapuche o Yámana).

Los objetos contemporáneos incluidos en la vitrina dedicada a los Selk'nam son tres cestas confeccionadas sobre junco con técnica de espiral (información inferida por las autoras que no se encuentra en el epígrafe) de diferente tamaño: la más grande contiene piedras y plumas, la mediana contiene valvas de moluscos y la más pequeña contiene hongos. El epígrafe solo menciona que fueron confeccionadas por Margarita Maldonado, pero no informa que se trata de una mujer selk' nam que realiza numerosas actividades relativas a la divulgación y educación sobre la cultura de sus ancestros (Maldonado, 2014) ni que las cestas fueron producidas entre 2005 y 2007 (M. Maldonado, comunicación personal, 2019).

No existe información escrita o visual que acompañe a estos artefactos contemporáneos salvo los mencionados epígrafes. El uso del término "réplica" reduce en cierto grado el carácter de autenticidad y de valor patrimonial del artefacto como objeto museográfico (Clifford, 1985; Kirschenblatt-Gimblett, 1998). De esta manera, no se conecta a estos objetos con ningún tipo de información escrita y/o visual que ayude a referenciarlos como creaciones producidas por integrantes de comunidades indígenas actuales, y así se oblitera no solo su 
pertenencia social fueguina sino también la continuidad pasado-presente en la confección de ciertos artefactos con morfologías y/o materias primas tradicionales.

\section{Discusión y reflexiones finales}

$\mathrm{Al}$ analizar los objetos patrimoniales indígenas exhibidos en el Museo del Fin del Mundo en su conjunto, encontramos distintas lógicas para su selección y exposición. Los objetos arqueológicos expuestos son considerados como representativos de los modos de vida de cada una de las sociedades indígenas representadas, tanto desde la antropología (Lothrop, 1928; Gusinde, 1982, 1986; Chapman, 2007) como desde la arqueología (Borrero, 1991; Orquera y Piana, 2015; Santiago y Salemme, 2016). Así, para representar a los cazadores de la estepa se seleccionaron artefactos de caza, como puntas de flecha y alisadores de astil, y artefactos de consumo de presas y procesamiento de materias primas, como raederas, machacadores y morteros, además de artefactos manufacturados con huesos de guanaco, la fuente principal de alimento de esos grupos. A su vez, la representación de los grupos canoeros implicó la selección de artefactos de caza de pinnípedos, como las puntas de arpón, y artefactos de consumo y procesamiento, como trinchetes y raederas. Así, los objetos arqueológicos exhibidos refuerzan la asociación de cada grupo con un modo de vida -cazador o canoero-, lo que constituye una estrategia didáctica efectiva, pero a su vez puede generar una correspondencia "sociedad-objeto" estática y esencialista (Vienni Baptista y Blasco, 2014). Los epígrafes de estos objetos arqueológicos son los más informativos de todos, ya que incluyen datos acerca del tipo de artefacto, su función, materia prima, antigüedad y el sitio arqueológico donde fue excavado.

Los objetos etnográficos, en cambio, son artefactos que representan el modo de vida de estas poblaciones de una manera más amplia, que incluye tanto la caza como la recolección. La vitrina dedicada a los Selk'nam incluye arcos y flechas, utilizados en las actividades de caza desarrolladas especialmente por los varones; pero también incluye cestas, utilizadas en las actividades de recolección de vegetales, hongos y moluscos, desarrolladas por las mujeres. Por otra parte, la vitrina yámana solo incluye cestas de origen etnográfico, utilizadas en las actividades de recolección, desarrolladas especialmente por las mujeres, pero no exhibe artefactos utilizados en la caza y la pesca, que constituían las actividades de subsistencia principales. De esta manera, en el caso selk'nam, los objetos etnográficos presentan un modo de vida más completo de caza y recolección, que solo aparece en el caso yámana cuando se incluyen los objetos contemporáneos. Los epígrafes relativos a estos objetos informan acerca del tipo de artefacto, materia prima y técnica de manufactura, pero solo en algunos casos informan acerca del artesano/a y la fecha de su confección.

Los objetos contemporáneos, por otro lado, parecen haber sido seleccionados para completar y/o ampliar la representación del modo de vida tradicional de estas sociedades indígenas. Así, en la vitrina dedicada a los Yámana se exponen "réplicas" de arpones, confeccionadas por un artesano contemporáneo (pero no presentado como tal en los epígrafes), de manera de incluir los elementos utilizados en la caza de pinnípedos que los objetos etnográficos no mostraban, y completar la representación del modo de subsistencia yámana. Por otro lado, en la vitrina dedicada a los Selk'nam se muestran "réplicas" de cestas confeccionadas por una artesana selk' nam contemporánea, que aumentan la cantidad de piezas similares en exhibición -de hecho, tres de ellas son 
contemporáneas y solo una es etnográfica-. La existencia de cestas etnográficas y contemporáneas podría de hecho señalar la continuidad de una práctica cultural ancestral (Kirschenblatt-Gimblett, 1998), sin embargo, el guion del museo no señala la persistencia de esta tradición visible en la cultura material, cortando los lazos con las sociedades indígenas contemporáneas (Rivolta et al. 2014). Además, los epígrafes relativos a estos objetos contemporáneos son los que menos información aportan: tipo de objeto, materia prima y nombre del artesano encargado de la manufactura (sin mencionar su identidad indígena).

La información escrita que acompaña estos objetos patrimoniales es de suma importancia, ya que es la que explicita el guion museográfico, ordena la exhibición principal, otorga sentido a los objetos expuestos y conecta las diferentes secciones de la exhibición. En este sentido, la palabra escrita corrobora y complementa a los objetos expuestos, dado que aporta información necesaria para su comprensión y contextualización.

La información visual incluida tiene distintos usos en las diferentes secciones de la exhibición: como vimos, en la sección \#2, dedicada al poblamiento de la región fueguina, se incluyen mapas, diagramas, dibujos y grabados; y en la sección \#3, dedicada a los Pueblos Originarios Fueguinos, se incluyen solamente fotografías etnográficas. Estas imágenes constituyen un caso paradojal: la mayoría carece de datos de autoría, fecha, localidad o nombres de los fotografiados, lo que reduce su valor documental al de la ilustración visual (Burke, 2005; Fiore y Varela 2009; Butto, 2019). Sin embargo, permiten visualizar los mismos tipos de objetos que se encuentran exhibidos siendo manipulados y accionados por los indígenas fueguinos fotografiados. De esta manera, la información visual corrobora y complementa la aportada por los objetos expuestos, contextualizándolos, sumando información y permitiendo ver ese tipo de objetos en acción.

De esta manera, el eje de la exhibición está puesto en los objetos patrimoniales, que son los que narran la historia y representan a los Pueblos Originarios Fueguinos, mientras los textos e imágenes conforman mecanismos de apoyo y contextualización de estos objetos, lo cual permite construir discursos verbales y visuales sobre ellos. En efecto, esta exhibición muestra elementos de las culturas y modos de vida de los Pueblos Originarios Fueguinos como una adaptación exitosa que comenzó en tiempos prehistóricos y continuó hasta entrado el siglo $\mathrm{XX}$, en tanto los mismos tipos de objetos son exhibidos en ambas secciones antropológicas/arqueológicas. Así, la representación de los indígenas fueguinos tiende a una esencialización que destaca ciertos diacríticos (Barth, 1976; Fiore y Varela, 2009) que caracterizarían a Yámanas y Selk'nam de manera diferente. Sin embargo, y a pesar de las críticas que recibió este modelo esencializador de la cultura -caracterizado por una visión normativa de ésta, un desconocimiento de las interacciones sociales y una homogeneización de los individuos-, es necesario reconocer que este enfoque resulta sumamente didáctico en la exhibición museográfica, ya que permite a los visitantes aprender sobre las culturas y modos de vida de los Pueblos Originarios Fueguinos de manera contextual, diacrónica y reflexiva (Quijada, 2012).

Por otro lado, el museo ofrece una conexión entre pasado prehistórico -evidenciado por los materiales arqueológicos- y momentos históricos -evidenciados en los materiales etnográficos- pero no ofrece un vínculo con el presente -evidenciado en los materiales contemporáneos-. La autoría y contemporaneidad de estos últimos están diluidas por falta de información en los epígrafes de los objetos y esto impide conectar los artefactos contemporáneos con los 
anteriores, así como informar que han sido producidos con otras funciones distintas a las tradicionales, que eran utilitarias. Esta falta de explicitación de la contemporaneidad de algunos objetos invisibiliza la identidad étnica de sus artesanos, a la vez que dificulta su asociación con las comunidades actuales de indígenas fueguinos, alienando las historias nativas (Rivolta et al., 2014). De esta manera, la extensión temporal de la historia de los Pueblos Originarios Fueguinos presentada en la exhibición no llega hasta el presente, lo que dificulta una verdadera conexión de los objetos patrimoniales prehistóricos e históricos con los contemporáneos realizados por personas pertenecientes a comunidades indígenas. Cabe notar, sin embargo, que este sesgo en la muestra ha sido trabajado a partir de la presentación de visitas guiadas por el Sr. Víctor Vargas Filgueira, Primer Consejero de la Comunidad Indígena Yagán Paiakoala de Ushuaia. ${ }^{10}$

A su vez, a lo largo de la exhibición museográfica resulta llamativa la ausencia de referencias a los encuentros violentos, las matanzas, el traslado de personas, el desmembramiento de familias, la transculturación y evangelización forzada y la apropiación de tierras que caracterizaron el proceso de colonización de Tierra del Fuego (Borrero, 1991; Chapman, 2007; Fiore y Varela, 2009; Orquera y Piana, 2015; Butto, 2019). Dado el ordenamiento cronológico de la exposición, que refiere a los misioneros y los exploradores de fines del siglo XIX, no es un dato menor la falta de referencias a estas consecuencias de la colonización para los Pueblos Originarios de la región. En tanto la exhibición museística permite producir la realidad de lo memorable, la omisión de esos procesos conflictivos y violentos puede entenderse como un silenciamiento (Crespo y Tozzini, 2014).

En conclusión, y dado que los objetos museográficos no portan significados inherentes, sino que dependen de la valoración y activación del patrimonio durante su exhibición, visita y discusión (Prats, 2004), encontramos en el Museo del Fin del Mundo un proceso de patrimonialización particular, centrado en los objetos arqueológicos y etnográficos, que oblitera la importancia de los objetos contemporáneos. Esta selección podría relacionarse con la antigua asociación del patrimonio con aquellos bienes "arcaicos", exóticos e inmemoriales, que destacaban por su belleza y autenticidad y que referían a los "otros culturales" (Endere, 2009; Boccara y Ayala Rocabado, 2011). Por ello, los objetos contemporáneos, aunque formen parte de la exhibición museográfica y, por lo tanto, hayan sido patrimonializados, ocupan un lugar de menor importancia, que solo completa la exhibición. Este proceso de patrimonialización parece haber sido desarrollado desde el museo, sin consulta ni participación de las comunidades indígenas, lo cual resultó en una exposición univocal (Rivolta et al., 2014). En ella, los grupos indígenas fueguinos se constituyen en "otros" objetivados, asociados al pasado e invisibilizados como agentes sociales activos en el espacio público dentro del museo y fuera de él (Boccara y Ayala Rocabado, 2011; San Martín, 2013; Fiore y Butto, 2019). Estas estrategias de incorporación de lo indígena al espacio museográfico a través de la invisibilización, folklorización, fetichización y mercantilización (Rodríguez de Anca, 2013) han sido referidas como "arqueologización" de los Pueblos Originarios (San Martín, 2013). Sin embargo, este término no se corresponde con los conceptos ni con las prácticas arqueológicas contemporáneas, que vienen apuntando a enfatizar las relaciones pasado-presente, la multivocalidad y la mirada crítica hacia el negacionismo de los genocidios en las Américas (Gnecco, 2001; Butto y Fiore, 2019), razón por la cual consideramos que se trata en realidad de un proceso de "fosilización", en el que los pueblos indígenas son tratados como "fósiles guía" de un pasado remoto sin relación con el presente.
10. Estas visitas guiadas no son reseñadas en este trabajo debido a que se iniciaron con posterioridad a nuestros trabajos de campo en el museo y exceden al propósito del presente escrito. Esperamos en un futuro próximo abordar este tema, a fin de profundizar el conocimiento sobre la divulgación de la exhibición museográfica. 
Para finalizar, consideramos que, pese a los sesgos aquí identificados y analizados, la exhibición de estos diferentes objetos patrimoniales -arqueológicos, etnográficos y contemporáneos- en la sección antropológica/arqueológica del Museo del Fin del Mundo permite a los visitantes tener un primer contacto con la existencia y características de los Pueblos Originarios Fueguinos de manera diacrónica, y con una didáctica tradicional, a la que gran parte del público está acostumbrado. Así, la exhibición aporta a construir conocimientos acerca de la presencia de estos pueblos en la configuración de la identidad fueguina y nacional, pero sobre todo abre potenciales oportunidades para una visión crítica y reflexiva sobre sus roles en el presente y el futuro de la región.

\section{Agradecimientos}

Nuestro agradecimiento a Martín Vázquez, Luis Orquera, Ernesto Piana, Estela Mansur y a Víctor Vargas Filgueira y los miembros de la Comunidad Yagán Paiakoala por su apoyo y aporte de información durante los trabajos de campo en Ushuaia. Agradecemos asimismo a Margarita Maldonado por aportarnos valiosa información sobre la producción de sus cestas. Agradecemos a los evaluadores del manuscrito, cuyos comentarios y recomendaciones bibliográficas permitieron mejorar y profundizar el escrito. 


\section{Q Referencias bibliográficas}

"Alonso González, P. (2017). El Antipatrimonio. Fetichismo y dominación en Maragatería. Madrid: Consejo Superior de Investigaciones Científicas.

» Barth, F. (1976). Los grupos étnicos y sus fronteras. Ciudad de México: Fondo de Cultura Económica.

» Baudrillard, J. (1975). The Mirror of Production. St. Louis: Telos Press.

»Belza, J. E. (1974). En la Isla del Fuego 1. Encuentros. Ciudad Autónoma de Buenos Aires: Instituto de Investigaciones Históricas de Tierra del Fuego.

» Boccara, G. y Ayala Rocabado, P. (2011). Patrimonializar al indígena. Imaginación del multiculturalismo neoliberal en Chile. Cahiers des Amériques latines, 2(67), 207-228.

» Borrero, L. (1991). Los Shelk'nam: su evolución cultural. Ciudad Autónoma de Buenos Aires: Búsqueda-Yuchan.

"Bourdieu, P. (2010). El sentido social del gusto. Elementos para una sociología de la cultura. Ciudad Autónoma de Buenos Aires: Siglo XXI.

"Bridges, L. (2005 [1948]). El último confín de la tierra. Ciudad Autónoma de Buenos Aires: Sudamericana.

"Burke, P. (2005). Visto y no visto. El uso de la imagen como documento histórico. Barcelona: Crítica.

» Butto, A. (2019). Huellas fotográficas de los pueblos originarios patagónico-fueguinos durante la conformación del Estado-nación argentino. En C. Hammerschmidt (Ed.). Patagonia literaria V. Representaciones de la identidad cultural mapuche (pp. 313-339). Potsdam: INOLAS Publisher.

" Butto, A., Saletta, M. J. y Fiore, D. (2018). Cultura visual de cazadores terrestres y marinos: fotografías, textos y artefactos arqueológicos de dos pueblos originarios fueguinos. Nuevo Mundo Mundos Nuevos, s/p. https://doi.org/10.400o/nuevomundo.72853

"Chapman, A. (2007). Los Selk'nam. La vida de los onas en Tierra del Fuego. Ciudad Autónoma de Buenos Aires: Emecé.

" Clifford, J. (1985). Objects and selves-an afterword. En G. Stocking (Ed.). Objects and others. Essays on museums and material culture (pp. 236-246). Madison: The University of Wisconsin Press.

》Consejo Internacional de Museos (2007). Estatuto. 22 ${ }^{\underline{a}}$ Asamblea General. Viena: ICOM.

»Crespo, C. y Tozzini, A. (2014). Memorias silenciadas y patrimonios ausentes en el Museo Histórico de El Hoyo, Comarca Andina del Paralelo $42^{\circ}$, Patagonia Argentina. Antípoda. Revista de Arqueología y Antropología, 19, 21-44.

》Endere, M. L. (2009). Algunas reflexiones acerca del Patrimonio. En M. Endere y J. Prado (Eds.), Patrimonio, ciencia y comunidad. Un abordaje preliminar en los partidos de Azul, Tandil y Olavarría (pp. 19-48). Olavarría: UNICEN.

»Fiore, D. y Butto, A. (2019). Fuegian museums and anthropological discourses: A comparison of the representations of indigenous societies from Tierra del Fuego in the two southernmost museums in the world (Museo del Fin del Mundo, Argentina, and Museo Antropológico Martín Gusinde, Chile). Museum Anthropology, 42(2), $125-144$.

»Fiore, D. y Varela, M. L. (2009). Memorias de papel. Una arqueología visual de las fotografías de pueblos originarios fueguinos. Ciudad Autónoma de Buenos Aires: Dunken. 
»Gnecco, C. (2001). Reflexión en tres actos sobre el museo. En D. Patiño (Ed.). Arqueología, patrimonio y sociedad (pp. 65-77). Popayán: Universidad del Cauca.

» Gusinde, M. (1982 [1931]). Los indios de Tierra del Fuego. Los Selk'nam. I y II. Ciudad Autónoma de Buenos Aires: CAEA.

» Gusinde, M. (1986 [1937]). Los indios de Tierra del Fuego. Los Yamanas. I-II-III. Ciudad Autónoma de Buenos Aires: Consejo Nacional de Investigaciones Científicas.

» Harris, E. (1991). Principios de estratigrafía arqueológica. Barcelona: Crítica.

» Kirschenblatt-Gimblett, B. (1998). Destination culture: Tourism, museums and heritage. Londres: University of California Press.

» Lothrop, S. K. (1928). The Indians of Tierra del Fuego. Nueva York: Museum of American Indian.

" Macdonald, S. (2006). A Companion to Museum Studies. Oxford: Blackwell Publishing.

» Maldonado, M. (2014). Entre dos mundos. Ushuaia: Editora Cultural Tierra del Fuego.

» Orquera, L. y Piana, E. (2015 [1999]). La vida social y material de los Yámana. Ushuaia: Monte Olivia.

» Prats, L. (2004). Antropología y patrimonio. Barcelona: Ariel.

"Quijada, M. (2012). Los museos de frontera de la provincia de Buenos Aires: Entre el gliptodonte y el indio poblador. Revista de Indias, 72(254), 131-176.

» Reca, M. (2016). Antropología y museos. Un diálogo contemporáneo sobre patrimonio. Buenos Aires: Editorial Biblos.

» Renfrew, C. y Bahn, P. (1998). Arqueología: teoría, métodos y prácticas. Madrid: Akal.

» Rivolta, M. C., Montenegro, M., Menezes Ferreira, L. y Nastri, J. (2014). Multivocalidad y activaciones patrimoniales en arqueología: perspectivas desde Sudamérica. Ciudad Autónoma de Buenos Aires: Fundación de Historia Natural Félix de Azara.

»Rodríguez De Anca, A. (2013). Políticas culturales y colonialidad. Acerca del régimen de visibilidad del Pueblo Mapuce en Neuquén. En C. Crespo (Ed.). Tramas de la diversidad. Patrimonio y pueblos originarios (pp. 21-38). Ciudad Autónoma de Buenos Aires: Prometeo.

» San Martín, C. (2013). Memorias que desarqueologizan. En C. Crespo (Ed.). Tramas de la diversidad. Patrimonio y pueblos originarios (pp. 101-135). Ciudad Autónoma de Buenos Aires: Prometeo.

"Santiago, F. y Salemme, M. (2016). Guanaco hunting strategies in the northern plains of Tierra del Fuego, Argentina. Journal of Anthropological Archaeology, 43, 110-127.

»Shelton, A. (2006). Museums and museum displays. En C. Tilley, W. Keane, S. Küchler, M. Rowlands y P. Spyer (Eds.). Handbook of material culture (pp. 480-499). Londres: Sage.

» Schiffer, M. (1972). Archaeological context and systemic context. American Antiquity, 37, 156-165.

» Smith, L. (2006). Uses of Heritage. Nueva York: Routledge.

» Tilley, C. (2006). Introduction. En C. Tilley, W. Keane, S. Küchler, M. Rowlands y P. Spyer, (Eds.). Handbook of material culture (pp. 1-6). Londres: Sage.

»Vienni Baptista, B. y Blasco, B. (2014). Museos y socialización del patrimonio arqueológico en Uruguay. Museologia e Patrimônio - Revista Eletrônica do Programa de Pós-Graduação em Museologia e Patrimônio, 7(2), 36-59. 